\title{
Correction to: Inhaled corticosteroids as treatment for adolescent asthma: effects on adult anxiety-related outcomes in a murine model
}

\author{
Jasmine I. Caulfield ${ }^{1,2,3} \cdot$ Allison M. Ching ${ }^{2}$ - Erin M. Cover ${ }^{2}$. Avery August ${ }^{4} \cdot$ Timothy Craig $^{5} \cdot$ Helen M. Kamens ${ }^{2,3}$. \\ Sonia A. Cavigelli ${ }^{2,3}$
}

Published online: 10 February 2021

(C) Springer-Verlag GmbH Germany, part of Springer Nature 2021

\section{Correction to: Psychopharmacology https://doi.org/10.1007/s00213-020-05666-x}

In the published paper, the co-author Helen M. Kamens' name included a typographical error that was inserted after the proofing stage.

The original article has been corrected.

Publisher's note Springer Nature remains neutral with regard to jurisdictional claims in published maps and institutional affiliations.

The online version of the original article can be found at https://doi.org/ $10.1007 / \mathrm{s} 00213-020-05666-\mathrm{x}$

Sonia A. Cavigelli

sac34@psu.edu

1 Huck Institute for Life Sciences, Pennsylvania State University, 101 Life Sciences Building, University Park, PA, USA

2 Department of Biobehavioral Health, Pennsylvania State University, 219 Biobehavioral Health Building, University Park, PA, USA

3 Center for Brain, Behavior, and Cognition, Pennsylvania State University, University Park, PA, USA

4 Department of Microbiology and Immunology, Cornell University, Ithaca, NY, USA

5 Allergy, Asthma \& Immunology Section, Department of Medicine and Pediatrics, Pennsylvania State University, Hershey, PA, USA 